\title{
Li- and Na-Doped NiO Thick Film for Thermoelectric Hydrogen Sensor
}

\author{
Woosuck SHIN, Masahiko MATSUMIYA, Fabin QIU, Noriya IZU and Norimitsu MURAYAMA \\ Synergy Materials Research Center, AIST, Shimo-Shidami, Moriyama-ku, Nagoya-shi 463-8560
}

\author{
Li 及び Na をドープした酸化ニッケル厚膜を用いた熱電水素センサー \\ 申 宇亟·松宮正彦·邱 法斌 ·伊豆典哉 ·村山宣光 \\ 産業技術総合研究所シナジーマテリアル研究センター，463-8560 名古屋市守山区下志段味穴ヶ洞 2266-98
}

\begin{abstract}
A novel thermoelectric gas sensor of $\mathrm{Li}$ - and $\mathrm{Na}$-doped $\mathrm{NiO}$ thick film coated with $\mathrm{Pt}$ as catalyst on half of its surface, was fabricated for hydrogen gas detection. When this sensor is exposed to air mixed with hydrogen gas, the catalytic reaction heats up the Pt-coated surface, and thermoelectric voltage appears across the hot and cold regions of the oxide film. The thick oxide film was printed on the alumina substrate with a viscous paste, a mixture of the nickel oxide powders doped with alkali ions and organic vehicle. The printed film was fired at $1000^{\circ} \mathrm{C}$ for $2 \mathrm{~h}$ and then the $\mathrm{Pt}$ thin film was deposited at room temperature by the rf sputtering method. The non-contact in situ temperature monitor used in this study enables the measurement of voltage signal and the temperature difference separately. The calculated thermopower of the thick oxide film is also discussed.

[Received June 12, 2002; Accepted August 9, 2002]
\end{abstract}

Key-words : Hydrogen, Gas sensor, Thermoelectric, Thick-film oxides, Pt catalyst

\section{Introduction}

In the next decade, concerns about global climate change and energy security will create the platform for the introduction of hydrogen to several niche markets, and ultimately, hydrogen and electricity will come from sustainable renewable energy resources, while fossil fuels will be the transitional resources during this period. The improvement of fuel cell technology will provide a basis for the establishment of the hydrogen option in both transportation and electricity supply markets. To ensure the safety of the hydrogen energy system, new hydrogen gas sensors for robust, reliable, and cost-effective devices for widespread use must be developed within a developing hydrogen infrastructure. In addition, they should be small, affordable and easy to implant on integrated circuits, such as film type, or integrated micro-machined hydrogen gas sensors. However, the present hydrogen sensors commercialized or under development are still very expensive and most of them are for very low hydrogen concentrations and useless above \% levels. ${ }^{1)}$

Recently, we have demonstrated a new thick-film-type thermoelectric (TE) gas sensor operating at room temperature for detecting 3\% hydrogen gas. ${ }^{2)}$ Since TE material can convert thermal energy to electrical work without any special structures, it is used for not only TE power generation, the classical application, but also sensor applications in the measurement of thermal signals or detection of infrared radiation signals. ${ }^{3)}$ The operating principle of our novel thick-film TE hydrogen sensor is similar to that in previous reports in which heat energy from a catalytic reaction is converted by the thermoelectric ${ }^{4)}$ or pyroelectric effect.5) First, the catalytic reaction produces heat, and then, analogous to thermocouples, a voltage difference is induced by the temperature gradient, $\Delta V=\alpha \Delta T$, where $\alpha$ is the thermopower (or Seebeck coefficient). The TE figure of merit is defined by $Z=\left(\alpha^{2} \sigma\right) / \kappa$, where $\sigma$ is the electrical conductivity and $\kappa$ is the thermal conductivity. A high $Z$ material is required for this TE gas sensor device; a large $\alpha$ induces a large voltage signal, a high $\sigma$ conductivity reduces noise, and a low $\kappa$ suppresses unwanted heat transfer. For our sensor device, $\mathrm{Li}$, $\mathrm{Na}$-doped $\mathrm{NiO}$ was used as the TE layer, which has been developed for high-temperature power generation. ${ }^{6), 7)}$

We report herein our study on this thick-film thermoele- ctric hydrogen gas sensor based on the $\mathrm{Li}, \mathrm{Na}$-doped $\mathrm{NiO}$ and a Pt catalyst. $\mathrm{NiO}$ is a good TE oxide (TEO). It is easy to control its electrical conductivity by alkali doping and the conductivity or thermopower is little affected by gas. Pt is selected as the catalyst for improving room temperature hydrogen selectivity, while TE materials may play an important role in activating the catalytic reaction. The performance test reported here will provide data on the response characteristics, speed and sensitivity, all of which will be advantageous for defining appropriate applications and guiding the engineering design of sensor packages and electronics. Also, the results related to cross-sensitivity, and the dependence on the device-operating temperature, which improves sensor reliability, are reported.

\section{Experimental procedures}

2.1 Material choice and device structure

The sensor is fabricated by screen printing the thermoelectric $\mathrm{Li}$, Na-doped nickel oxide, TEO, on an alumina substrate. The TEO layers were printed with a viscous paste, which was a mixture of the $\mathrm{NiO}$ powders doped with $\mathrm{Li}, \mathrm{Na}$ ions and organic vehicle. The nominal composition of the $\mathrm{NiO}$ powder was $5.0 \mathrm{~mol} \% \mathrm{Na}$, and 2.0 mass $\% \mathrm{Li}_{2} \mathrm{O}$.7) The organic vehicle was a blend of terpineol and ethyl cellulose. The size of the apertures in the net was 200 mesh, and the snap-off value (the distance between the net and the substrate) was $1 \mathrm{~mm}$. By changing the number of printing times, the thickness of the TEO film was controlled. After every printing, a 5 min drying at $200^{\circ} \mathrm{C}$ was carried out and then the sample was finally fired at $1000^{\circ} \mathrm{C}$ for $2 \mathrm{~h}$.

To achieve high hydrogen selectivity, the Pt layer was used as a catalyst for the designed hydrogen element. Pt thin film was deposited at room temperature by rf sputtering on the half of the TEO surface, using a metal mask. The distance between the substrate and the target was $70 \mathrm{~mm}$, with the flow of Ar gas at $20 \mathrm{cc} / \mathrm{min}$, and the working pressure at $2.3 \times 10^{-1} \mathrm{~Pa}$. The structure of the sensor device is shown in Fig. 1. The Pt-catalyst layer effectively converts $\mathrm{H}_{2}$ to $\mathrm{H}_{2} \mathrm{O}$ with the $\mathrm{O}$ atoms adsorbed on the $\mathrm{Pt}$ surface, and gives out heat energy, resulting in the temperature difference across the sensor. The TEO layer works as an energy transducer and builds up the voltage signal, $V_{\mathrm{s}}$. Electrical 
point pads of $1 \mathrm{~mm}$ diameter were prepared on top of the $\mathrm{Pt}$ catalyst and TEO using Ag paste, and Au wires of $0.1 \mathrm{~mm}$ diameter were connected to the pads to read the voltage signal.

The most important parameter of the sensor device is the dimensions of the catalyst layer. The substrate is 22 length $\times 11$ width $\times 1$ thickness $\mathrm{mm}^{3}$, the TEO layer is $18 \times 5 \mathrm{~mm}^{2}$, and the Pt catalyst covers half of the TEO layer, i.e., $9 \times$ $5 \mathrm{~mm}^{2}$. This set of dimensions is optimized by pre-experiments and used throughout this study. The thicknesses of TEO and the Pt layer are important parameters in this study and will be discussed in detail here.

\subsection{Characterization}

For the response test, gas mixtures containing ppm or \% level hydrogen can be conveniently obtained by using a gas syringe. Here, a chamber with a rubber septum is used into which dry air can be introduced. A pure sample gas is drawn into a calibrated gas syringe, with a needle pushing through the septum. The desired concentration could be obtained by injecting a known volume of pure gas into a known volume of dry air. Flows of the mixture gas and dry air are changed by electrically controlled valves. A four-way valve directs two flows, mixture gas and clean air, alternately into a measuring chamber so that the response speed of the sensor can be obtained in a second by switching one gas stream to the others quickly.

To evaluate and investigate the properties of TEO and catalyst for this thermoelectric gas sensor device, the voltage signal $V_{\mathrm{s}}$ and the built-up temperature difference $\Delta T$ on the surface of the device must be measured separately.

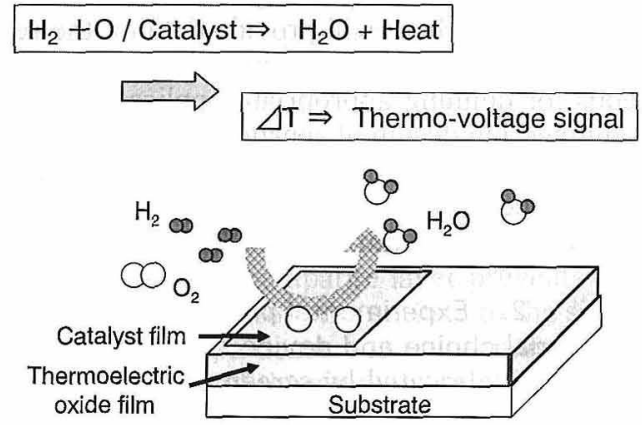

Fig. 1. Schematic of thick-film thermoelectric gas sensor showingthe principle of selective hydrogen detection.
Non-contact in situ temperature monitoring enabled us tò measure $V_{\mathrm{s}}$ and $\Delta T$ separately through the window of the measurement chamber using an infrared image camera (Nikon, LAIRD-270A). Surface temperatures near the voltage lead pad were measured to evaluate $\Delta T$.

The entire measurement system including the camera system, the gas-flow manipulation system and the multichannel data acquisition system is simultaneously controlled by a personal computer. For the material characterization, XRD (Rigaku, RINT2100) and FE-SEM (JEOL, JSM $6335 \mathrm{~F}$ ) were used.

\section{Results and discussion}

\subsection{Thick-film thermoelectric oxide}

The thickness of the NiO TEO film increased with increasing number of printing times. When the printing time was $1,2,4$, or 6 times, the thickness of the film was 13.3 , $25.6,35.5$, or $56 \mu \mathrm{m}$, respectively. The thickness of the film was the average value obtained by SEM observation of the cross section, as shown in Fig. 2. A thickness of about 10 $\mu \mathrm{m}$ can be achieved by single printing under the conditions described in this study.

We fixed the thickness at $60 \mu \mathrm{m}$ (6 printing times) for all thick-film samples for the gas sensor device, which gave the lowest resistance and the reduced noise. When the thickness was increased to 80 and $100 \mu \mathrm{m}$, the final film surface became very rough and had many cracks, which increased the resistance of the device and suppressed the following process. It was much easier to control the film thickness by adjusting the number of printing times than by other parameters, for example, viscosity of the paste, mesh size of the net, and the snap-off value, etc.

The thickness of the Pt catalyst could not be observed directly on the surface of the TEO film since the roughness of the thick film is larger than the thickness of the Pt thin film. However, the Pt film on the polished Si wafer deposited in the same batch was used to predict the thickness, which corresponded to $20 \mathrm{~nm}$. The thickness of the Pt film on the polished Si wafer was evaluated from the deposition time-thickness relation (a preliminary experiment in which a series of films with thicknesses of 100,300 and $700 \mathrm{~nm}$ were made and their cross sections directly observed by FE-SEM). Atomic force microscopy of $\mathrm{Pt}$ film on the $\mathrm{Si}$ wafer revealed that small particles with a diameter of around $20 \mathrm{~nm}$ agglomerate, covering the whole surface. The $\mathrm{Pt}$ film catalyst was much thicker than reported ${ }^{8)}$ in which films of several nanometers thickness were suggested.

As shown in Fig. 2, the grains of the TEO thick film con-
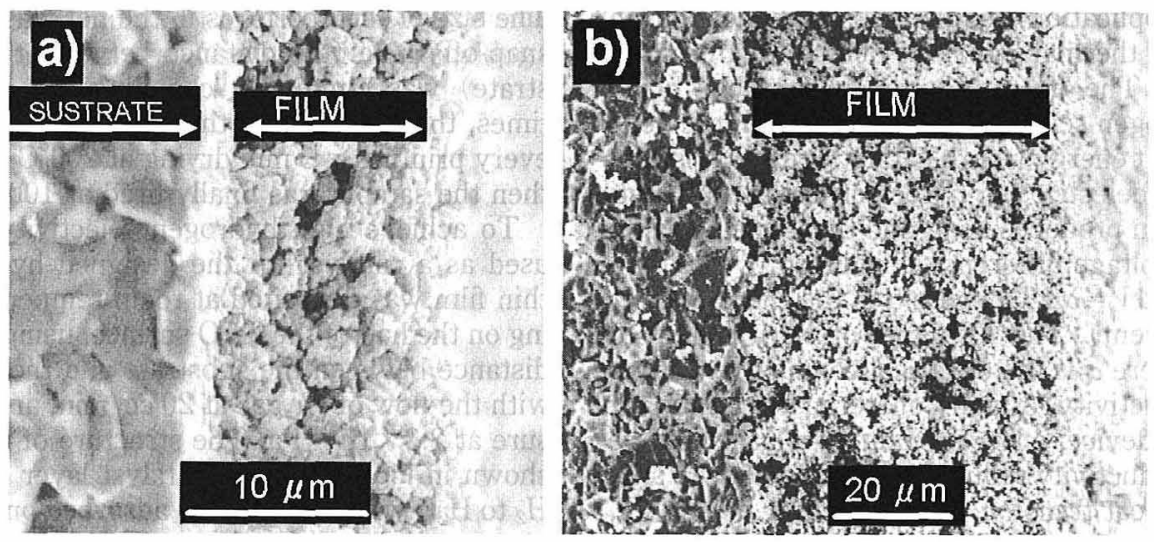

Fig. 2. SEM images of the cross section of the thick-film NiO on alumina substrate after sintering at $1000^{\circ} \mathrm{C}$ for $2 \mathrm{~h}$, for a) single and b) 6 times' printing. 
tacted each other by neck. Their size was about $1 \mu \mathrm{m}$ or less and was almost same to the size of the starting powder. When the sintering temperature was increased up to $1250^{\circ} \mathrm{C}$ for $2 \mathrm{~h}$, the grain size increased to $2-3 \mu \mathrm{m}$, but the resistance was as high as $10 \mathrm{M} \Omega$. The sintering conditions of $1000^{\circ} \mathrm{C}$ for $2 \mathrm{~h}$ were the optimum considering the thermoelectric power and the resistance of the sensor device. At a lower sintering temperature of $900^{\circ} \mathrm{C}$, the resistance became higher than that at $1000^{\circ} \mathrm{C}$. It is suggested that active volume diffusion at the sintering temperature of $1000^{\circ} \mathrm{C}$ induces the grain contact each other, and that much $\mathrm{Li}$ is lost at much higher temperatures.

The resistance read from the voltage leads for thick films sintered at the conditions of $1000^{\circ} \mathrm{C}$ for $2 \mathrm{~h}$ was $0.5-1.0 \mathrm{M} \Omega$ at room temperature. Assuming that the contact resistance is zero, the resistivity of the thick film is $15-30 \Omega \cdot \mathrm{cm}$, which is almost the same as that of bulk sample with the same nominal composition, i.e., about $1-10 \Omega \cdot \mathrm{cm}$, from a previous report. ${ }^{7)}$ The lattice constant of $\mathrm{NiO}$ changes with the $\mathrm{Li}$ content, as revealed by XRD analysis. ${ }^{6), 7)}$ From the XRD patterns of the thick-film $\mathrm{NiO} /$ alumina, the lattice constant calculated from the (111) plane for the cubic lattice was $0.41656 \mathrm{~nm}$, corresponding to $0.6 \mathrm{~mol} \% \mathrm{Li}$ doping. From this resistivity analysis, the expected thermoelectric power, Seebeck coefficient, is about $0.4 \mathrm{mV} / \mathrm{K}$.

\subsection{Response of gas sensor device}

The measured voltage signal, $V_{\mathrm{s}}$, and the built-up temperature difference, $\Delta T$, for the thermoelectric hydrogen sensor, $\mathrm{Pt} / \mathrm{NiO} /$ alumina, when exposed to $1 \% \mathrm{H}_{2}$ /air mixture gas at $25^{\circ} \mathrm{C}$, were $0.079 \mathrm{mV}$ and 0.15 , respectively, as shown in Fig. 3(a). Response time $T_{90}$ and recovery time $T_{90 \mathrm{D}}$ are defined as follows: $T_{90}$ is the time to reach $90 \%$ of $V_{\mathrm{s}}, T_{90 \mathrm{D}}$ is the time to decrease to $10 \%$ of $V_{\mathrm{s}} . T_{90}$ and $T_{90 \mathrm{D}}$ were $70 \mathrm{~s}$ and $50 \mathrm{~s}$, respectively. This response is very fast considering room temperature operation. The response of other gas sensors such as a semiconductor type at room temperature, is much slower; $T_{90 \mathrm{D}}$ in particular is usually about 5-10 min. ${ }^{9), 10)}$ Both $T_{90}$ and $T_{90 \mathrm{D}}$ became a slightly faster at $40-50 \mathrm{~s}$ even at temperatures exceeding $65^{\circ} \mathrm{C}$.

Figure 3(b) shows the temperature change at the two voltage leads. $\Delta T$ in Fig. 3 (a) was plotted from these raw data. The temperature at the two voltage leads $\mathrm{A}$, the Pt-catalyst side, and B, the bare-TEO-surface side, increased monotonically when hydrogen gas flows, and decreased in the same manner; however; $\Delta T$ in Fig. 3 (a) showed very clear signals. After $T_{90}$, the voltage signal reached $V_{\mathrm{s}}$ level, and after $T_{90 \mathrm{D}}$, the voltage signal reached zero level again. These clear responses were also obtained under other conditions, such as different hydrogen concentrations and different operating temperatures, with high reliability.

The reason for the clear $V_{\mathrm{s}}$ signal is that the temperature difference was used as the sensing mechanism; in contrast, other sensors that use the resistance change with temperature as the sensing mechanism need very careful control of the operating temperature. For hot-coil (catalytic-combustion) sensors that use the resistance change for sensing, the signal will be extremely small (for example, the temperature coefficient of $\mathrm{Pt}$ resistivity is only $\sim 4 \times 10^{-3} /{ }^{\circ} \mathrm{C}^{11)}$ ) and noisy due to temperature fluctuations. The signal-to-noise ratio for the response curve in the Fig. 3 (a) is 16 . This is the unique feature of the novel thermoelectric gas sensor device in this study, which gives a stable signal level and a high signal-to-noise ratio. This operating mechanism is also advantageous for the temperature stability of the signal as will be discussed later.

However, the response characteristics at room temperature are not reproducible. They depend mostly on the surface state of the $\mathrm{Pt}$ catalyst and its history. This problem was solved by increasing the operating temperature up to
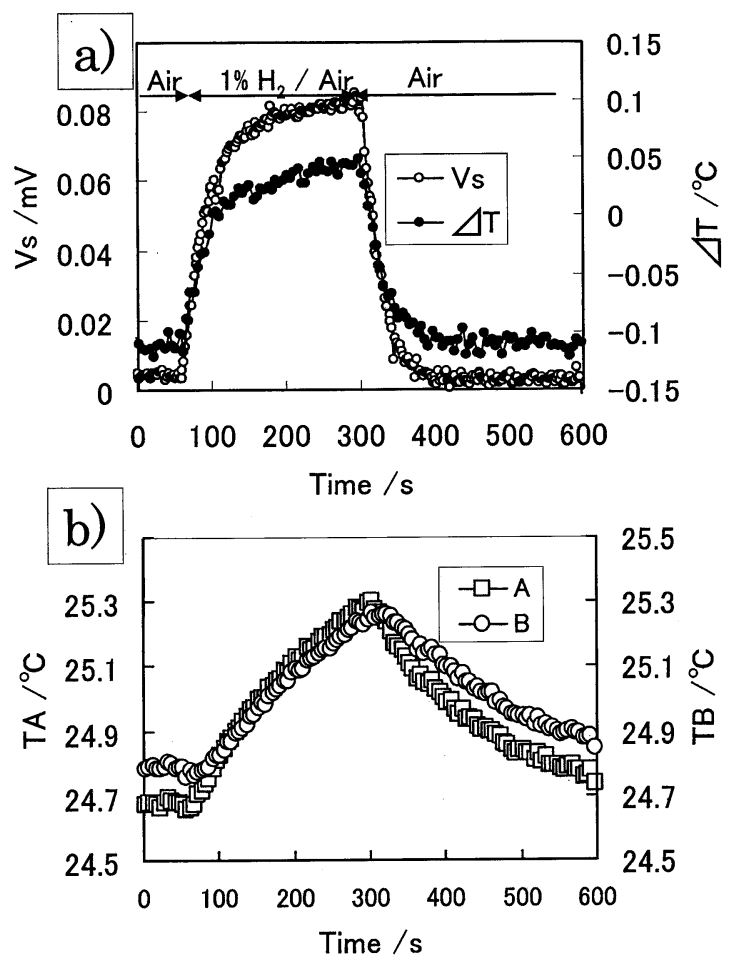

Fig. 3. Response of thermoelectric gas sensor, $\mathrm{Pt} / \mathrm{NiO} /$ alumina to $1 \% \mathrm{H}_{2}$ /air at a temperature of $25^{\circ} \mathrm{C}$, a) voltage signal, $V_{\mathrm{s}}$, and temperature difference, $\Delta T$, and $\mathrm{b}$ ) temperature changes near the two voltage electrodes, $\mathrm{A}$ and $\mathrm{B}$.

$100^{\circ} \mathrm{C}$, where the surface of the catalyst can refresh by itself. High-temperature operation also has other advantages as discussed in the next section.

\subsection{Linearity for gas concentration}

Figure 4(a) shows the operating temperature dependence of the voltage signal of the thermoelectric hydrogen sensor, $\mathrm{Pt} / \mathrm{NiO} /$ alumina, for 1,3 and $10 \% \mathrm{H}_{2} /$ air. Near room temperature, $V_{\mathrm{s}}$ is very low and there is no clear relationship between voltage and gas concentration. However, as the temperature increased, the voltage signal increased due to the enhanced catalytic activity, and saturated at around $85^{\circ} \mathrm{C}$. In the temperature range of $85-150^{\circ} \mathrm{C}, V_{\mathrm{s}}$ was nearly constant and its temperature dependency was extremely small. It is proven that $\mathrm{Pt}$ catalytic activity reaches its maximum at $85^{\circ} \mathrm{C}$. For instance, for $1 \% \mathrm{H}_{2} /$ air, comparing the $V_{\mathrm{s}}$ at room temperature, the $V_{\mathrm{s}}$ became 10 times higher. The resistance of the sensor device, $R$, which is the origin of the noise, also reduced from $1 \mathrm{M} \Omega$ to $100 \mathrm{k} \Omega$ with increasing temperature. The $R$ values for $25,85,100$ and $145^{\circ} \mathrm{C}$ were $1061,207,143$ and $58.8 \mathrm{k} \Omega$, respectively.

In this flat region of $85-150^{\circ} \mathrm{C}$, the linearity of $V_{\mathrm{s}}$ vs. gas concentration is also very good; thus, the present sensor shows much promise for device design and application, considering that other gas sensor devices generally show an exponential behavior for the concentration vs. signal plot.9),10) Since the temperature dependence of the thermoelectric power of the TEO in this temperature region is very small, the signal difference can be attributed to the heat generated by the oxidation reaction. Therefore, these temperature dependences were mostly due to the catalytic activity of the exothermic reaction, the oxidation of the gas. For practical applications, the temperature of the gas sensor device must be under such control, as PID control, and therefore most sensors have an auxiliary circuit inside the chip or the con- 



Fig. 4. Voltage signal, $V_{\mathrm{s}}$, of the thermoelectric gas sensor, $\mathrm{Pt} /$ $\mathrm{NiO} /$ alumina, for 1,3 and $10 \% \mathrm{H}_{2}$ /air, at temperatures of $85-$ $150^{\circ} \mathrm{C}$. a) $V_{\mathrm{s}}$ at different operating temperatures, b) $V_{\mathrm{s}} \mathrm{vs} . \mathrm{H}_{2}$ concentration at $100^{\circ} \mathrm{C}$.

trol board. However, this TE gas sensor has a stable and constant $V_{\mathrm{s}}$ for the temperature region of $85-150^{\circ} \mathrm{C}$. Thus, a heater line designed with a pre-set heater power of around $115^{\circ} \mathrm{C}$ will be sufficient for applications, allowing a temperature change of +35 to -30 depending on the operation environment.

\subsection{Detection limit for hydrogen gas in air}

The lower explosion limit of hydrogen is $4 \%$ in air. Therefore, as a hydrogen leakage detector or an alarm for protection against explosion, an alarm level is usually set for gas concentrations between $0.1 \%$ and $4 \%$ from a practical point of view. For the thermoelectric hydrogen sensor, the percent-level detection of hydrogen in the range of $1-10 \%$ was very appropriate and showed good linearity, as shown in Fig. 4(b). The lower detection level is also very important and will be directly related to the size for the thermoelectric gas sensor. For sensors with a catalyst size of $0.9 \times 0.5$ $(=0.45) \mathrm{cm}^{2}$ used in this study, the lower detection limit was below $250 \mathrm{ppm}$.

Figure 5 shows the response curves of the sensor for 250 and $1000 \mathrm{ppm}$ hydrogen at $100^{\circ} \mathrm{C}$. The linearity of $V_{\mathrm{s}}$ for the given gas concentrations is excellent, e.g., $1 \%$ hydrogen gas corresponds to $1 \mathrm{mV}$, and 1000 and $250 \mathrm{ppm}$ correspond to 0.10 and $0.24 \mathrm{mV}$, respectively. The results suggest that the thermoelectric sensor introduced in this report is suitable for actual applications even in its present form.

\section{Summary}

A new hydrogen sensor based on the thermoelectric oxide of $\mathrm{Li}$ - and $\mathrm{Na}$-doped $\mathrm{NiO}$ has been fabricated using the screen printing method. The thermoelectric hydrogen sen-

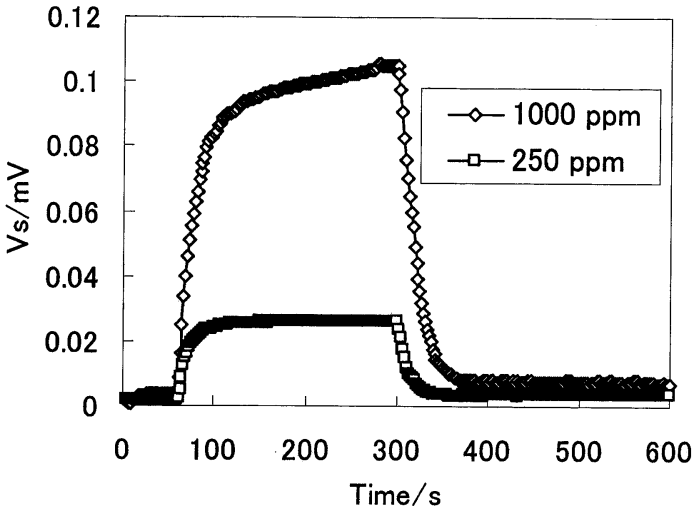

Fig. 5. Voltage signals, $V_{\mathrm{s}}$, of the thermoelectric gas sensor, $\mathrm{Pt} /$ $\mathrm{NiO} /$ alumina, for 250 and $1000 \mathrm{ppm} \mathrm{H}_{2} /$ air at a temperature of $100^{\circ} \mathrm{C}$.

sor, $\mathrm{Pt} / \mathrm{NiO} /$ alumina, showed voltage signal and built-up temperature difference for $1 \% \mathrm{H}_{2} /$ air mixture gas. At $25^{\circ} \mathrm{C}$, the voltage signal and temperature difference were 0.079 $\mathrm{mV}$ and $0.15^{\circ} \mathrm{C}$, respectively, and the signal-to-noise ratio was 16. The increase in operating temperature up to the range of $85-150^{\circ} \mathrm{C}$ made the catalytic activity more stable, and the response characteristics were also improved. A very clear voltage signal of $1 \mathrm{mV}$ for $1 \%$ hydrogen gas was observed, and the sensor showed extremely small temperature dependence. The sensor possesses a good linear relationship between the voltage signal and the gas concentration at this operating temperature range.

The lower detection limit of the sensor was found to be below $250 \mathrm{ppm}$, and the sensor provides an output level of 0.1 to $10 \mathrm{mV}$, which corresponds to practical gas concentrations of hundred ppm order to several percent with a high signal-to-noise ratio. From these results, we conclude that this sensor is the most promising candidate for fast and affordable hydrogen leakage detectors for fuel cell driving systems.

Acknowledgment This research was partially supported by the Industrial Technology Research Grant Program for 2000 from the New Energy and Industrial Technology Development Organization (NEDO) of Japan.

\section{References}

1) Shin, W., J. High Pressure Gas Safety Inst. Jpn., 39, 48 (2002) [in Japanese].

2) Shin, W., Imai, K., Izu, N. and Murayama, N., Jpn. J. Appl. Phys., 2, 40, L1232-34 (2001).

3) Baltes, H., Sens. Act. A, 56, 179-92 (1996).

4) McAleer, J. F., Moseley, P. T., Bourke, P., Norris, J. O. and Stephan, R., Sens. Act., 8, 251-56 (1985).

5) Hall, J. P., Whatmore, R. W. and Ainger, F. W., Ferroelectrics, 54, 551-56 (1984).

6) Shin, W. and Murayama, N., Jpn. J. Appl. Phys. 2, 38, L1336-38 (1999).

7) Shin, W. and Murayama, N., Mater. Lett., 45, 302-06 (2000)

8) Papadopoulos, C. A. and Avaritsiotis, J. N., Sens. Act., B 28, 201 (1995).

9) Ihokura, K. and Watson, J., "Stannic Oxide Gas Sensor," CRC Press, Inc., Boca Raton (1994).

10) Reddy, C. V. G. and Manorama, S. V., J. Elctrochem. Soc., 147[1], 390-93 (2000).

11) Ross, R. B., "Metallic Materials Specification Handbook," Fourth ed., Chapman Hall, London (1992). 